\title{
Bud Formation and the Inducibility of Pseudo-mycelium Outgrowth During Release from Stationary Phase in Candida albicans
}

\author{
By DAVID R. SOLL AND GLENN W. BEDELL \\ Department of Zoology, University of Iowa, Iowa City, Iowa 52242, U.S.A.
}

(Received 9 May 1978)

\begin{abstract}
The kinetics of bud formation at $25^{\circ} \mathrm{C}$ and germ tube formation at $37^{\circ} \mathrm{C}$ were examined in populations of Candida albicans released from stationary phase by dilution into fresh nutrient medium. Evidence is presented for four separate isolates and three different defined media that: (i) cells do not deplete the media of growth-limiting nutrients when they enter stationary phase; (ii) cells accumulate as singlets when they enter stationary phase, presumably at a point early in the cell cycle; (iii) daughter cells do not separate from mother cells during the first three to four cell divisions following release from stationary phase at $25^{\circ} \mathrm{C}$; and (iv) released cells cannot be induced to form germ tubes by an increase in temperature once they have formed their first bud at $25^{\circ} \mathrm{C}$. The relationships between the lack of cell separation, the inducibility of tube formation and stationary phase are discussed.
\end{abstract}

\section{INTRODUCTION}

The dimorphic pathogen Candida albicans can grow either as a budding yeast or as an invasive pseudo-mycelium (Sherr \& Weaver, 1953). Recently, Chaffin \& Sogin (1976) presented evidence which indicated that conversion from the budding yeast form to the pseudo-mycelial form could be induced by an increase in temperature only after cells had entered stationary phase in an amino acid containing defined medium (Lee et al., 1975). This observation was of interest for several reasons. First, several fungi are known to accumulate at a particular stage of the cell cycle when they enter stationary phase in liquid medium (Hartwell, 1974; Soll et al., 1976). Therefore, the transformation from the budding yeast form to the pseudo-mycelial form may be restricted to a particular stage in the cell cycle. Second, some fungi produce growth inhibitors (Lingappa \& Lingappa, 1967; Yarger et al., 1974) and putative regulatory molecules (Ferguson \& Soll, 1977) at stationary phase which may play developmental roles in their life-cycles. The inducibility of pseudomycelia may be under the control of such factors. We have therefore examined the conditions leading to the cessation of cell multiplication at stationary phase and the growth characteristics of cultures released from stationary phase by dilution into fresh medium at low temperature, which results in bud formation, and at high temperature, which results in germ tube formation.

\section{METHODS}

Growth and maintenance of cultures. Our major experimental strain of Candida albicans, 3153A, was obtained from Dr Steven Sogin of the University of Houston, Houston, Texas, U.S.A.; strains C136, c141 and 157 were obtained from Dr Helen Buckley of Temple University, Philadelphia, Pennsylvania, U.S.A. Stock cultures were maintained on nutrient agar [containing (per litre): $10 \mathrm{~g}$ glucose, $10 \mathrm{~g}$ Bacto-peptone, $1 \mathrm{~g} \mathrm{MgSO}_{4} .7 \mathrm{H}_{2} \mathrm{O}, 2 \cdot 2 \mathrm{~g} \mathrm{KH}_{2} \mathrm{PO}_{4}, 1 \mathrm{~g} \mathrm{~K}_{2} \mathrm{HPO}_{4}, 1 \mathrm{~g}$ yeast extract, $20 \mathrm{~g}$ Bacto-agar]. Cells from these cultures were inoculated into $25 \mathrm{ml}$ defined medium at $25^{\circ} \mathrm{C}$ in $125 \mathrm{ml}$ Erlenmeyer flasks and shaken at $200 \mathrm{rev}$. $\mathrm{min}^{-1}$

Vol. 108, No. 1 was issued 14 September 1978 
in a New Brunswick rotary shaker at $25^{\circ} \mathrm{C}$. When these initial cultures reached mid-exponential phase, $1 \mathrm{ml}$ was re-inoculated into $30 \mathrm{ml}$ fresh medium and shaken at $25^{\circ} \mathrm{C}$. This latter culture and subsequent subcultures were used for experimental purposes. Three media were examined: an amino acid containing defined medium developed by Lee et al. (1975), here designated 'Lee's medium'; a modified version of Lee's medium lacking all the amino acids except proline (increased to $10^{-2} \mathrm{M}$ ), designated 'simplified Lee's medium'; and a minimal medium containing biotin, glucose and $\mathrm{NH}_{4} \mathrm{Cl}$ in phosphate-buffered saline, developed by Land et al. (1975), designated 'Land's medium'.

Release from stationary phase. To release cells from stationary phase into the budding yeast form, stationary phase cells were diluted into fresh medium at $25^{\circ} \mathrm{C}$ to an initial cell concentration of $4 \times 10^{\circ}$ to $7 \times 10^{6} \mathrm{ml}^{-1}$ and shaken. To release cells into the pseudo-mycelial form, stationary phase cells were diluted into fresh medium at $37^{\circ} \mathrm{C}$ to an initial cell concentration of $4 \times 10^{8}$ to $7 \times 10^{8} \mathrm{ml}^{-1}$ and shaken.

\section{RESULTS}

\section{Growth kinetics in defined media}

At $25^{\circ} \mathrm{C}$, cells of our major experimental strain 3153A grew exclusively in the budding yeast form in Lee's medium, in simplified Lee's medium and in Land's medium. In Lee's medium and in simplified Lee's medium, the generation time was $2 \mathrm{~h}$ and the final cell concentration at stationary phase was $1 \times 10^{8}$ to $2 \times 10^{8} \mathrm{ml}^{-1}$. In Land's medium the generation time was approximately $3 \mathrm{~h}$ and the final cell concentration at stationary phase was 10 -fold less than in the other two media, being $1 \times 10^{7}$ to $2 \times 10^{7} \mathrm{ml}^{-1}$. Similar growth kinetics in these three media were obtained for strains c136, c141 and c157.

\section{Cells do not enter stationary phase in defined media as a result of the depletion of nutrients}

When fresh exponential phase cells were diluted into cell-free medium from stationary phase cultures of strain 3153A grown in Lee's medium or simplified Lee's medium, the cells grew at maximal rates to final concentrations close to the stationary phase levels obtained in the initial cultures. When fresh exponential phase cells were diluted into cell-free medium from stationary phase cultures grown in Land's medium, cells divided for several generations to a stationary phase concentration of approximately half that found in the initial culture.

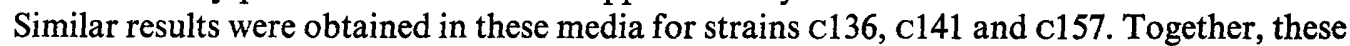
data demonstrate that $C$. albicans does not stop multiplying in defined media as a result of the complete depletion of nutrients from the supporting medium, corroborating similar observations made by Saltarelli (1973). The fact that nutrients are still present in stationary phase cultures probably explains why stationary phase cells do not decrease in volume or mass, do not lose viability, and are capable of rapid pseudo-mycelial outgrowth for more than $300 \mathrm{~h}$ in stationary phase.

\section{Cells accumulate as singlets in stationary phase}

In a mid-exponential phase culture of strain 3153A in either Lee's medium or simplified Lee's medium, the number of spheres [any mother cell or bud] was more than double the number of cells [mother cell plus attached bud(s)]. This was due to the very high proportion of budding cells in the population. For instance, in Lee's medium, singlets (single cells with no buds) made up only 20 to $30 \%$ of an exponential phase cell population, whereas doublets made up approximately 40 to $50 \%$, triplets approximately $25 \%$, and clusters of four or more spheres approximately $5 \%$.

When a growing culture reached a cell concentration of approximately $5 \times 10^{7}$ to $1 \times 10^{8}$ $\mathrm{ml}^{-1}$, the rate of growth began to decrease and after another 2 to $4 \mathrm{~h}$, the rate was about zero. At stationary phase, the number of spheres approached the number of cells since cells accumulated as unbudded singlets. After $24 \mathrm{~h}$ in stationary phase, cultures contained approximately 60 to $80 \%$ unbudded singlets, and after $72 \mathrm{~h}$, between 80 and $90 \%$ singlets. 


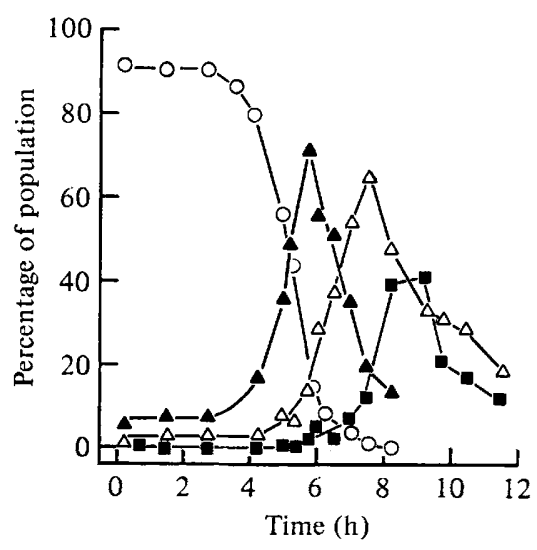

Fig. 1. The proportions of unbudded and budded cells in a culture released from stationary phase after $72 \mathrm{~h}: \bigcirc$, the percentage of singlets in the population; $\Delta$, doublets; $\Delta$, triplets plus quadruplets; w, clusters containing five or more spheres. Proportions were determined by dividing the concentrations of each class of cells by the total cell concentration; a 'cell' was considered to be either an unattached singlet or a cluster of two or more tightly attached spheres.

The concentration of spheres at stationary phase remained stable for more than $300 \mathrm{~h}$. Similar results were obtained for strains c136, c141, and c157.

\section{Cells form buds semi-synchronously when released from stationary phase}

When stationary phase cells of strain 3153A were diluted into fresh Lee's medium at $25^{\circ} \mathrm{C}$, the majority remained unbudded for approximately $4 \mathrm{~h}$. Then, in the next $2 \mathrm{~h}, 90 \%$ of the cells formed buds. The $T_{50}$ for bud formation (the time at which $50 \%$ of the unbudded cell population has formed buds) was approximately $4.5 \mathrm{~h}$ for released $24 \mathrm{~h}$ stationary phase cultures and $5 \mathrm{~h}$ for released $72 \mathrm{~h}$ stationary phase cultures (Fig. 1).

\section{After release from stationary phase, cells do not separate during the first rounds of bud formation}

After the first round of bud formation, the mature daughter cells did not separate from the mother cells. Rather, the population reached a maximum of over $70 \%$ doublets at $5.75 \mathrm{~h}$ (Fig. 1) and then, instead of separating into unbudded singlets, both the attached mother cells and mature daughter cells formed new buds (Fig. 1 and Fig. 2a). A septum could be distinguished between attached mother cells and mature daughter cells, but not between mother cells and newly forming buds (Fig. 2a). The lack of cell separation after the first round of bud formation is best visualized by plotting the proportion of triplet plus quadruplet clusters in the population (Fig. 1). Triplets plus quadruplets began appearing in the population after $5.5 \mathrm{~h}$ and reached a maximum of $65 \%$ of the cell population by $7 \cdot 5 \mathrm{~h}$. At this time triplets made up $20 \%$ and quadruplets $45 \%$ of the population; doublets made up $20 \%$ and singlets less than $2 \%$. Clusters of five or more attached spheres began appearing after $7 \mathrm{~h}$ reaching a maximum of over $40 \%$ of the cell population by $8.5 \mathrm{~h}$ (Fig. 1). At this time, over $60 \%$ of the total spheres in the population were contained in this large-cluster fraction.

Large multiple bud clusters did not separate after vigorous vortexing, but they could be separated completely into singlets and doublets by sonication. After sonication there was no blebbing at the disrupted connections indicating that septation was at least partially complete. However, sonicated cells did exhibit a slight distortion, probably due to the mechanical disruption of the connection between mother and daughter cells. The separated 

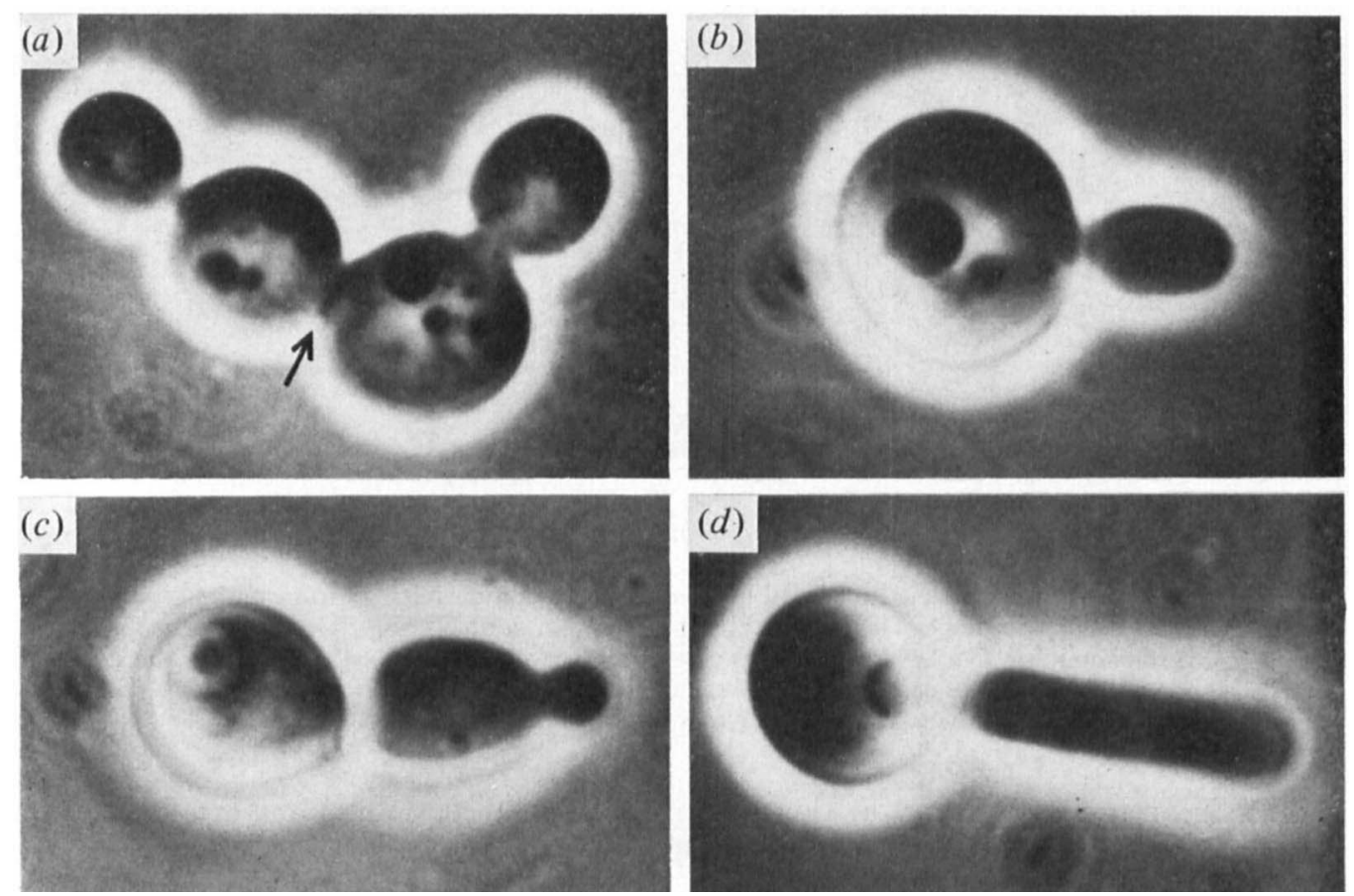

Fig. 2. Photomicrographs: (a) A multiple bud cluster $8 \mathrm{~h}$ after release from stationary phase at $25^{\circ} \mathrm{C}$ : the cluster is composed of unseparated mother and daughter cells both forming buds; the arrow points at the septum between mother and daughter cells. (b) A cell with a newly forming germ tube at $37^{\circ} \mathrm{C}$. (c) A cell after the germ tube has reverted to a multiple bud cluster at $37^{\circ} \mathrm{C}$ : the new bud always forms at the apex of the reverted germ tube. $(d)$ A growing stable pseudo-mycelium at $37^{\circ} \mathrm{C}$. Magnification: $\times 5500$ in $(a, c, d) ; \times 7250$ in $(b)$.

cells were perfectly viable. After separation, cells from $8.5 \mathrm{~h}$ cultures multiplied at the same maximal rate and reached the same final stationary phase density as unsonicated parallel cultures.

\section{In cultures released from stationary phase, unbudded singlets reappear after $8 \mathrm{~h}$}

After released cultures had been incubated for $8 \mathrm{~h}$ at $25^{\circ} \mathrm{C}$ in fresh nutrient medium, the proportion of singlets was less than $1 \%$ of the cell population. In the experiment plotted in Fig. 3, the concentration of singlets decreased from $7 \times 10^{6} \mathrm{ml}^{-1}$ at the time of dilution to $5 \times 10^{4} \mathrm{ml}^{-1}$ after $8 \mathrm{~h}$, a decrease of more than two orders of magnitude. During this initial $8 \mathrm{~h}$ period, the total cell (or cluster) concentration remained relatively stable (Fig. 4), but the concentration of spheres began to increase after $4 \mathrm{~h}$, when the first buds appeared, and continued to increase thereafter (Fig. 4). After $8 \mathrm{~h}$, the concentration of cells also began to increase (Fig. 4) as unbudded singlets again appeared in the population; concomitantly, the proportion of the population of clusters larger than doublets began to decrease (Fig. 1).

It is unlikely that the increase in singlets after $8 \mathrm{~h}$ resulted from the division of previously formed singlets since the singlet population increased from $5 \times 10^{4}$ to $3.5 \times 10^{6} \mathrm{ml}^{-1}$ in $1.75 \mathrm{~h}$ (Fig. 3); this would represent a doubling time of approximately $17 \mathrm{~min}$, a highly unlikely rate of cell division for a yeast. It is also unlikely that the increase in the singlet concentration is due to the complete dissociation of unseparated sphere clusters since the concentration of these clusters remained relatively stable after $8 \mathrm{~h}$. It is far more likely that the radical increase in singlets after $8 \mathrm{~h}$ is the result of the separation of a limited number of buds from large clusters. It is plausible that separation may be restricted to newly formed buds after $8 \mathrm{~h}$, but data are not available for this distinction. 


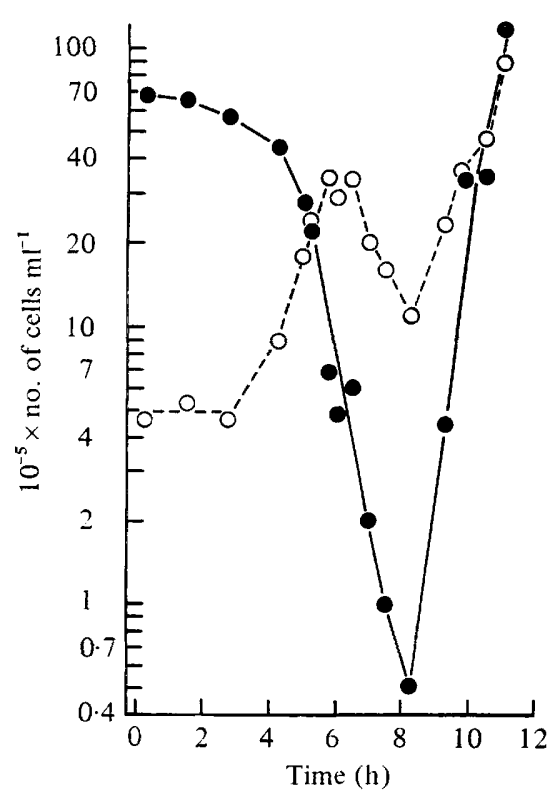

Fig. 3

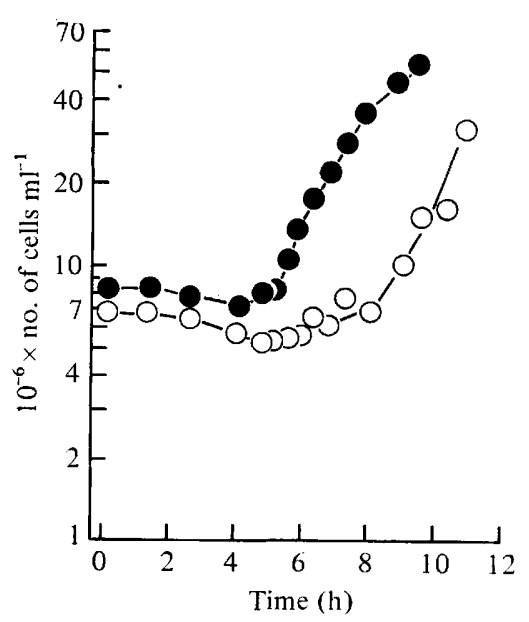

Fig. 4

Fig. 3. The concentrations of singlets $(\Theta)$ and doublets $(O)$ in a culture released from stationary phase after $72 \mathrm{~h}$. The concentrations of cells were determined by haemocytometer counts.

Fig. 4. The concentrations of spheres [any mother cell or bud, O] and cells [mother cell plus attached bud(s), $O]$ in a culture released from stationary phase after $72 \mathrm{~h}$.

\section{Multiple budding is not peculiar to strain 3153A, to Lee's medium or to a particular point in stationary phase}

Multiple budding was also tested for in the separate isolates c136, c141 and c157 in Lee's medium. In all cultures, cells accumulated as singlets at stationary phase and, when released into fresh medium at $25^{\circ} \mathrm{C}$, proceeded through several rounds of budding without concomitant bud separation. When cells grown to stationary phase in simplified Lee's medium and in Land's medium were diluted into fresh simplified Lee's medium or Land's medium, respectively, they formed multiple buds. Therefore, multiple budding is not a peculiarity of either strain 3153A or Lee's medium.

Cells from early $(24 \mathrm{~h})$ and late $(100 \mathrm{~h})$ stationary phase cultures were also tested for multiple budding when released into fresh medium at $25^{\circ} \mathrm{C}$. Cells from both cultures exhibited the same kinetics of multiple bud formation as the $72 \mathrm{~h}$ cultures already described in detail, indicating that the multiple budding phenomenon is not restricted to a specific portion of stationary phase.

\section{Initiation of pseudo-mycelium formation}

Chaffin \& Sogin (1976) demonstrated that over $90 \%$ of the cells of a stationary phase culture of C. albicans grown in Lee's medium could be induced to form pseudo-mycelium by dilution into prewarmed growth medium followed by incubation at $37^{\circ} \mathrm{C}$; exponential phase cultures could not be induced to form pseudo-mycelium by this temperature shift. We repeated these experiments and obtained the same results. When cells from a culture growing exponentially at $25^{\circ} \mathrm{C}$ were diluted into prewarmed medium and incubated at $37^{\circ} \mathrm{C}$, short germ tubes (Fig. $2 \mathrm{~b}$ ) appeared after $100 \mathrm{~min}$ in less than $5 \%$ of the cell population (Fig. 5). These early germ tubes were transient and reverted to a multiple bud form (Fig. $2 c$ ) 


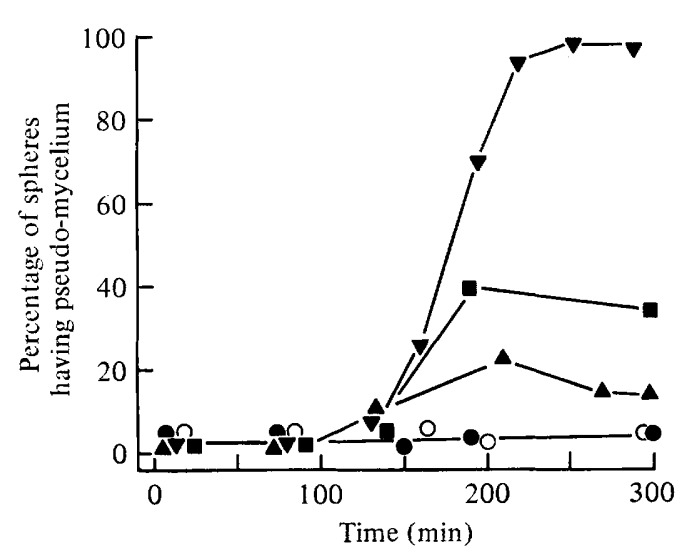

Fig. 5

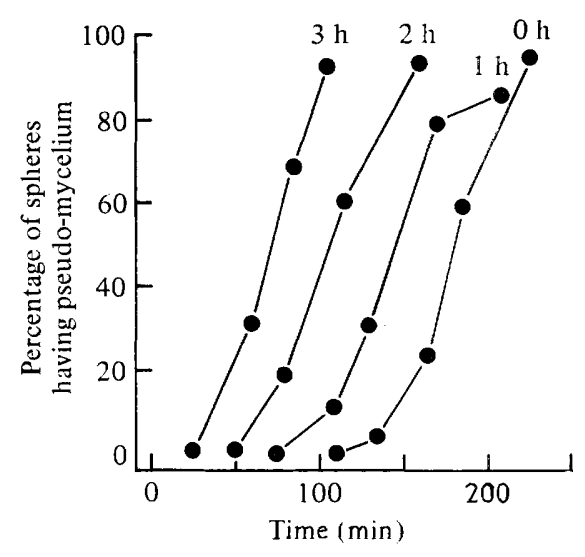

Fig. 6

Fig. 5. Pseudo-mycelium induction in exponential phase, transition to stationary phase, and stationary phase cultures. Cells from cultures at $25^{\circ} \mathrm{C}$ were diluted into fresh medium at $37^{\circ} \mathrm{C}$ and the formation of pseudo-mycelium was scored. A sphere was scored as having a pseudo-mycelium if it possessed an elongate evagination the length of which was equal to or greater than the diameter of the mother cell. $\boldsymbol{\theta}$, Mid-exponential phase; $O$, late-exponential phase; $\boldsymbol{\Delta}$, mid-transition to stationary phase, when the growth rate began to decrease; $\boldsymbol{\square}$, late-transition to stationary phase, when the growth rate approached zero; $\nabla, 24 \mathrm{~h}$ after the growth rate had decreased to approximately zero.

Fig. 6. Pseudo-mycelium induction in cells released from stationary phase. Released cells were incubated at $25^{\circ} \mathrm{C}$ in fresh nutrient medium for $0,1,2$ or $3 \mathrm{~h}$ (as indicated) and then incubation was continued at $37^{\circ} \mathrm{C}$. Zero time on the abscissa represents the time at which the culture was shifted to $37^{\circ} \mathrm{C}$.

after another $100 \mathrm{~min}$. When incubated for prolonged periods at $37^{\circ} \mathrm{C}$, these cultures continued to multiply as multiple bud clusters.

When the generation time of a culture at $25^{\circ} \mathrm{C}$ began to decrease as it entered stationary phase, a higher proportion of cells could be induced to form germ tubes when diluted into, and incubated in, medium at $37^{\circ} \mathrm{C}$ (Fig. 5). However, a significant proportion of these germ tubes were still transient and reverted to a multiple bud form. After $24 \mathrm{~h}$ in stationary phase, over $90 \%$ of the cell population could be induced to form long, stable germ tubes (Fig. $2 d$ ). Approximately $140 \mathrm{~min}$ after the shift to $37^{\circ} \mathrm{C}$, the first elongated germ tubes appeared in the population (Fig. 5). After $175 \mathrm{~min}, 50 \%$ of the cells possessed germ tubes and after $210 \mathrm{~min}, 90 \%$. These germ tubes did not revert to the multiple bud form; rather, they continued to grow for several hours at $37^{\circ} \mathrm{C}$ as pseudo-mycelia.

When cultures were released from stationary phase by dilution into fresh nutrient medium at $25{ }^{\circ} \mathrm{C}$, they could still be induced to form stable germ tubes by a temperature shift during the first $3 \mathrm{~h}$ incubation at $25^{\circ} \mathrm{C}$ (Fig. 6). For every hour spent in nutrient medium at $25^{\circ} \mathrm{C}$, the time required for germ tube formation after transfer to $37^{\circ} \mathrm{C}$ decreased by $35 \mathrm{~min}$. Thus, in cultures incubated for $0,1,2$ and $3 \mathrm{~h}$ at $25^{\circ} \mathrm{C}$, the $T_{50}$ values for germ tube formation (the time at which $50 \%$ of the cells formed germ tubes) at $37^{\circ} \mathrm{C}$ were $180,145,105$ and $70 \mathrm{~min}$, respectively (Fig. 6). There was no significant change in the synchrony of germ tube formation during this initial period since the slopes of the plots in Fig. 6 are approximately equal.

After $4 \mathrm{~h}$ at $25^{\circ} \mathrm{C}, 30$ to $50 \%$ of a released stationary phase cell population formed germ tubes $100 \mathrm{~min}$ after a temperature shift to $37^{\circ} \mathrm{C}$; however, these germ tubes were completely transient and reverted to multiple bud clusters (Fig. $2 c$ ) in another $100 \mathrm{~min}$. After $5 \mathrm{~h}$ at $25^{\circ} \mathrm{C}$, less than $1 \%$ of a released stationary phase cell population could be induced to form germ tubes by a temperature shift to $37^{\circ} \mathrm{C}$. The same was true for released cultures 
after 6 to $13 \mathrm{~h}$ incubation at $25^{\circ} \mathrm{C}$. Therefore, loss of the capacity for germ tube induction by a temperature shift correlates closely with the appearance of the first bud.

\section{DISCUSSION}

We have presented evidence that when $C$. albicans cells in the yeast form enter stationary phase at $25^{\circ} \mathrm{C}$, they accumulate as unbudded singlets, indicating that cells in stationary phase may be blocked at a point early in the cell cycle, as is the case for Saccharomyces cerevisiae (Hartwell, 1974). When $C$. albicans cells are released from stationary phase by dilution into fresh medium at $25^{\circ} \mathrm{C}$, they synchronously form buds, and when released by dilution into fresh medium at $37^{\circ} \mathrm{C}$, they synchronously form germ tubes (Lee et al., 1975; Chaffin \& Sogin, 1976). Chaffin \& Sogin (1976) previously presented evidence that a temperature shift could induce tube formation in cells growing in a complete amino acid containing medium (Lee et al., 1975) only after the cells had entered stationary phase. We have confirmed these observations using three additional $C$. albicans isolates and two additional media which contain only one amino acid, proline. Therefore, together, these observations indicate that a relationship may exist between the cessation of cell division and the capacity to induce the formation of pseudo-mycelium in $C$. albicans. Since stationary phase cells may be blocked at a point early in the cell cycle, a relationship may also exist between inducibility of germ tubes and a stage in the cell cycle.

When stationary phase cells were released by dilution into fresh medium at $25^{\circ} \mathrm{C}$, they progressed through several rounds of semi-synchronous bud formation without cell separation, resulting in multiple bud clusters. By 6 to $8 \mathrm{~h}$ after release, over $98 \%$ of all spheres were tightly attached to other spheres, and singlets had virtually disappeared from the cell population. Vigorous vortexing of cell cultures at this time did not separate multiple bud clusters, but sonication separated them into viable singlets and doublets which were slightly distorted. Similar results have been obtained for the dissociation of bud clusters by sonication in Saccharomyces cultures (Morris, 1966; Pringle \& Mor, 1975). The above observations on $C$. albicans indicate that cell separation or septum formation is aberrant or incomplete during the first three to four rounds of bud formation after release from stationary phase.

The two phenotypic characteristics of stationary phase cells which we have discussed, the unique capacity to form germ tubes at $37^{\circ} \mathrm{C}$ and the lack of cell separation at $25^{\circ} \mathrm{C}$, may be related. The lesion in the cell separation mechanism may reflect a phenotypic characteristic of stationary phase cells which is a prerequisite for the induction of pseudo-mycelium outgrowth. This may involve incapacity to synthesize one or more of the polysaccharide components of the septum (Cabib \& Bowers, 1971).

We have also demonstrated that when $C$. albicans cultures are released from stationary phase at $25^{\circ} \mathrm{C}$, they can be induced to form germ tubes by a shift to $37^{\circ} \mathrm{C}$ for only the first $3 \mathrm{~h}$ incubation at $25^{\circ} \mathrm{C}$. Once buds begin to form, i.e. after 4 to $5 \mathrm{~h}$ at $25^{\circ} \mathrm{C}$, pseudomycelium outgrowth can no longer be induced by a shift to $37^{\circ} \mathrm{C}$. These observations indicate that the early pathways for bud formation and germ tube formation are common and that between 4 and $5 \mathrm{~h}$ after release at $25^{\circ} \mathrm{C}$, a commitment point is passed after which cells cannot be induced to form pseudo-mycelium until the cells again enter stationary phase. The mechanism of this exclusion process is now under investigation.

The authors are indebted to Ms Elizabeth Loeb and Mr Mark Stasi for their participation in parts of this project. This investigation was supported by a Biomedical Science Support Grant FR-07035 from the General Research Support Branch, Division of Research Resources, Bureau of Health Professions, Education and Manpower Training, National Institutes of Health, and by a grant from the National Science Foundation, no. BMS7415019. 


\section{REFERENCES}

CABIB, E. \& Bowers, B. (1971). Chitin and yeast budding. Localization of chitin in yeast bud scars. Journal of Biological Chemistry 246, 152-159.

Chaffin, W. L. \& Sogin, S. J. (1976). Germ tube formation from zonal rotor fractions of Candida albicans. Journal of Bacteriology 126, 771-776.

Ferguson, R. \& Solt, D. R. (1977). Soluble factors and the regulation of early rate-limiting events in slime mold morphogenesis. Experimental Cell Research 106, 159-165.

HARTWELL, L. (1974). Saccharomyces cerevisiae cell cycle. Bacteriological Reviews 38, 164-198.

Land, G. A., MCDonald, W. C., StJernholm, R. L. \& FriedmaN, L. (1975). Factors affecting filamentation in Candida albicans: changes in respiratory activity of Candida albicans during filamentation. Infection and Immunity 12, 119-127.

LeE, K. L., BuCKLeY, H. R. \& CAMPBell, C. (1975). An amino acid liquid synthetic medium for development of mycelial and yeast forms of Candida albicans. Sabouraudia 13, 148-153.

LingAPPA, B. T. \& LingAPPA, Y. (1967). Alkaloids as self inhibitors of fungi. Nature, London 214, 516-517.

MORRIS, E. O. (1966). Aggregation of unicells: yeasts. In The Fungi, vol. II, pp. 63-82. Edited by G. C. Ainsworth and A. Sussman. New York: Academic Press.

Pringle, J. R. \& Mor, J. (1975). Methods for monitoring the growth of yeast cultures and for dealing with the clumping problem. Methods in Cell Biology XI, 131-168.

Saltarelli, C. G. (1973). Growth stimulation and inhibition of Candida albicans by metabolic byproducts. Mycopathologia et mycologia applicata 51, 53-63.

SherR, G. H. \& Weaver, R. H. (1953). The dimorphism phenomenon in yeasts. Bacteriological Reviews 17, 51-92.

Soll, D. R., YARGer, J. \& Mirick, M. (1976). Stationary phase and the cell cycle of Dictyostelium discoideum in liquid nutrient medium. Journal of Cell Science 20, 513-523.

Yarger, J., Stults, K. \& Soll, D. R. (1974). Observations on the growth of Dictyostelium discoideum in axenic medium: evidence for an extracellular growth inhibitor synthesized by stationary phase cells. Journal of Cell Science 14, 681-690. 